\title{
THE PORTFOLIO - A MODERN METHOD FOR FORMATIVE EVALUATION
}

\author{
V. Mircheva*, Iv. Prokopov, M. Legurska \\ Department of Information and In-Service Training of Teachers, Sofia University \\ "St. Kliment Ohridski", Sofia, Bulgaria
}

\begin{abstract}
The article presents the idea of using the portfolio as an opportunity to fully document the process of developing students' competencies. Its possibilities as a tool for formative assessment, are commented. On the basis of this type of formative assessment the competencies of the student are determined, which gives an idea of the achievements of each of them at the end of a certain stage of the educational process. The motivating function of the portfolio is also considered. The results of a survey conducted among pedagogical specialists are also presented, the aim of which is to prove the possibilities of the portfolio as a tool for formative assessment in the educational process.
\end{abstract}

Key words: students, portfolio, formative assessment, educational technology, feedback.

\section{INTRODUCTION}

How to evaluate the achievements of students in fulfilling the set goals in education? - This is a key issue that is at the heart of educational discussions. The analyzis shows above all the desire for continuous improvement of state standards for assessing student achievement, search and experimentation of new strategies and systems for assessment, development of quality assessments, assessment tests, the forming, and summarizing functions of assessments.

The basis of the assessment process is to determine the progress of students, assess their knowledge, achievements, and competencies in a particular subject area. Emphasis is placed on the situations that are most appropriate for the student to express their talent and abilities, as well as on the rules for demonstrating the evidence obtained.

The introduction of an effective and objective system for quality control and evaluation is an

\footnotetext{
*Correspondence to: Vessela Mircheva, Sofia University "St. Kliment Ohridski", Department of Information and In-service Training of Teachers, 1619, Sofia; 224, Tsar Boris III Blvd., Phone: +359886444433, e-mail:v.mircheva@abv.bg
}

important condition for the development of the school education system. A quality assessment system requires: assessment of cognitive skills, knowledge and applicable abilities; evidencebased assessment - valid, reliable and fair related to opportunities.

The goals of the modern educational process are not related to the learning of a volume of knowledge by students, but also to practical activities for the formation of skills and competencies. Regarding change, the emphasis is on interaction, communication, dialogue and partnership - not only between teacher and student, but also between students. All this leads to a change in the role of the assessment from assessment of knowledge and end results - it is transformed into assessment of the overall development and achievements of the student assessment of their actions and relationships.

The meaning of the formative assessment consists in the possibility for observation and timely correction of the student's activity, i.e., the error can be useful if detected immediately. According to I. Velchev, assessment is formative when the information received from it is used as a factor for adapting training in the 
direction of achieving certain educational goals (1).

Formative assessment is an ongoing process that allows evidence to be gathered about the strengths and weaknesses of learning, focusing on what students can do, rather than on their weaknesses and mistakes. The assessment is accurate and stimulates the performances. This method of assessment provides peace of mind and increases the efficiency of the educational process.

Assessment is formative when the information received from it is actually used to adapt the training according to certain educational goals. Teachers and students can give feedback on progress and weaknesses, problems which lead to a reduction in the gap between the real and expected level.

In order for the formative assessment to be effective, it is important to be positive, as it creates the necessary security for the student to be himself. The main role in its realization is played by the feedback, through which reflective behavior is built, which guarantees its success.

In order for the feedback to be effective, it must provide information not only for the purposes of education but also to accumulate evidence of what the student has achieved. It bridges the gap between them.

Features of the feedback are: constant, timely and obligatory informative; supported by rules; point the strengths and weaknesses of the action; determine criteria for assessment and self-assessment constructive in order to have a meaningful dialogue; respecting the dignity of the student, i.e., lack of fear of failure; leading the student to self-knowledge in order to develop his intellectual abilities; giving the student the right to choose to form communicative competence; striving for a higher level of success for each student; positively oriented to the specific achievement or difficulty.

Properly implemented formative assessment builds skills for self-assessment, student autonomy, which is the result of purposeful preparation. If those who receive the feedback are able to accept, realize, and make sense of it, then the goal is achieved.
In the modern school, it is extremely important that assessment is generally based on positivism and encouragement. These are the natural approaches that build the student's ideas about his own abilities. So he feels confident and takes the initiative to overcome difficulties. Encouragement helps to form selfesteem by strengthening the student's faith in his own strengths and abilities. It is important for students' achievements to be noticed. According to M. Andreev, as an expression of self-awareness, self-esteem has a significant impact on various manifestations of personality. In the relationship between teachers and students in the learning process, the self-assessment of one's own personal qualities is closely related to the assessment of others. And this has its impact on the nature of these relationships (2).

Formative assessment stimulates students' intellectual efforts, promotes their peace of mind, gives a clear idea of the student's own movement in the areas of current and future development, builds the mechanisms of reflection and generally pulls the student forward.

The most suitable methods for carrying out the formative evaluation are the portfolio and the mirror evaluation. The portfolio collects and presents evidence of the students' work, which allows for the gradual monitoring of the development of each of them - achievements and difficulties. This approach is best suited for conscious feedback. Objectivity is achieved, which predisposes and does not stress students, but motivates them.

Unlike the traditional methods used in the classroom, which determine the teacher as the center of the educational process, the training aimed at the individual interests of students most clearly indicates the basic principle of working with the help of a portfolio. Through the portfolio approach, the method is imposed as an important tool for the constant development of the learner's competencies. In the context of the portfolio, documenting the training and its results is much more than collecting documents, products, tests, essays or pictures.

From a methodological point of view, through the portfolio, it is necessary not only to preserve a set of information, but also to place the object in the appropriate context. This 
means that each document in the portfolio needs to be accompanied by data that include information about the purpose, outcome and most of all the real progress of the training. The most important process for the portfolio should take place during the documentation and this is the development of the process of "reflection". Students are able to reflect on the learning process, to document their main achievements and discoveries, to make a connection between their knowledge and previous experience, as well as to change the direction of work depending on the results of previous learning and extracurricular activities. According to W. Serbin, the portfolio is something more than gathering evidence for training. It means learning tasks, programs, achievements. It includes analyzis and reflections, arguments, case studies, summaries and notes of the teacher about teaching and the student about learning. Perhaps this is the reason why some authors accept it as a concept and not as a simple folder with documentation. The fact that the student will select the information about himself, will support and present it, helps to increase the level of his self-knowledge and helps build his own personality (3).

The portfolio, which is developed with the specific goal of formative assessment of the student, serves as a presentation to the class and the parent community. Due to its nature, once created, it should be constantly updated and changed according to the higher goals for which it will serve. The portfolio is never complete. According to the subject, the portfolio for formative assessment is personal, and according to the carrier it can be electronic or a folder on paper.

As a tool for formative assessment, it includes two subsections:

$>$ the attitude of the author (student) to the different types of activities according to the teachers, parents, classmates, other leaders in the respective fields;

$>$ the student's self-assessment of the specific activity and its results.

The portfolio has elements that are mandatory: the goals, criteria, the author's production, including tests and materials, as well as selfassessment of the overall work. It also contains elements that are optional: developments that the author himself has decided to include. The reviewer respects the author's choice and thus acquires autonomy.

The main purpose of the portfolio is the formative assessment of the educational process and mandatory - assessment for the purposes of the program. The portfolio method aims to present the building up of a certain competence. What will be the evaluation process needs to be determined at the start of the portfolio development work. The evaluation process will be based on the rules initially set. The intentions are aimed at assessing the overall development process, not the individual evidence.

When evaluating the portfolio, it is important to define instructions for compliance with the evaluation criteria, which should be taken into account, whether it is self-evaluation or peer feedback. In the student portfolio, the evaluation criteria are determined after discussion in class at the beginning of the school year and are divided into several groups:

$>$ Content criteria: the idea of the portfolio as a whole is to allow for a complete documentation of the competence development process, by carefully selecting the evidence to be included.

$>$ structure criteria: the key to success in the idea of lifelong learning, understood as part of career development, lies in practicing a structured and well-documented reflection, I.e. reflection on what has been achieved.

$>$ criteria regarding the external design: the portfolio is a personal document according to the desire and imagination of the teacher or student.

$>$ presentation criteria: public presentation involves synthesizing the documents and grouping them according to a pre-set goal.

Only if the presentation is very well structured will the listeners or readers get a complete picture of the author's acquired competencies. The presentation of evidence of progress builds a holistic view of its development.

It can be summarized that students have a positive attitude towards formative assessment by presenting a portfolio and a perceived need for the exchange of ideas and communication. The presence of documents proving 


\section{MIRCHEVA V., et al.}

competencies necessarily corresponds to a higher level of development. The knowledge that students acquire will have a direct impact on their activities.

\section{RESEARCH METHODOLOGY}

In order to check how effective, the use of a portfolio is for the purpose of assessing students, a survey was conducted with 551 teachers from four districts in the country Sofia, Blagoevgrad, Kyustendil, Yambol. The survey consisted of 17 questions.

The main goal of the research is to prove the possibilities of the portfolio as a tool for formative assessment in the educational process.

Research tasks:

$>$ To study and analyze the state of the problem, including the new regulations related to portfolio valuation.

$>$ To study the opinion of teachers about the effectiveness of the portfolio as a modern method of assessment.

$>$ To analyze the data from the surveys and to summarize the results.

The questionnaire survey of teachers about the possibilities of the portfolio, as a tool for formative assessment in the educational process, gives the opportunity to pedagogical specialists to express their opinion and attitude on the discussed problem. The research also involves collecting data on the attitudes of teachers to implement activities related to the possibilities of the portfolio, as a tool for formative assessment in the educational process and provides an opportunity to establish the competencies of students and what difficulties they encounter in practice.

The survey includes questions related to: the topicality of the activities for using the portfolio as a tool for formative assessment in the educational process at school; the legislation on civic education; the forms and organization of these activities; common difficulties; qualification needs; opportunities to improve the quality of students' preparation for self-assessment.

The survey data are a necessary and sufficient basis to draw conclusions about the attitude of teachers to the problems of portfolio opportunities, as a tool for formative assessment in the educational process and to seek solutions to improve existing practices related to school activities.
The questionnaire contains 17 questions, of which 15 with a structured answer and 2 with a free answer. Of the structured answer questions, 15 require only one answer.

The questionnaire is structured in three thematic blocks.

First block - questions aimed at establishing the professional and socio-demographic status of the pedagogical specialists who participated in the survey.

Second block - questions that aim to reveal the possibility of self-assessment of students through a portfolio, as a tool for formative assessment in the educational process, highlighting the strengths and weaknesses and opportunities for self-improvement.

Third block - questions about the attitude of pedagogical specialists to the possibilities of the portfolio, as a tool for formative assessment of students.

\section{RESULTS AND ANALYSIS}

The passport block of questions (from №1 to №7) is presented at the beginning of the questionnaire. They allow us to analyze data on the age and gender characteristics of pedagogical specialists. They are a starting point for analyzing empirical data.

Of the pedagogical specialists who participated in the study, $91 \%$ were women and $9 \%$ were men. This distribution of participants confirms a well-known but not very favorable trend in the teaching profession - its feminization.

In the age structure of the surveyed persons more than half of the pedagogical specialists $(30 \%)$ are aged from 45 to 50 , and almost equally (12 and $15 \%$ ) are distributed between 35-40 and 40-45 years of age. In the next group: $16 \%$ of the participants in the study are under the age of $60,22 \%$ are younger teachers representing 26-35-year-olds.

According to the acquired professional qualification degree (PQD), teachers are distributed as follows: $30 \%$ of the respondents have a fifth PQD. The percentage of holders of a fourth PQD is 26 and respectively a third PQD - 23\%. The percentage at the second level is 12 and can be explained by the fact that the educational system still employs teachers who received a second grade-qualification before 1996 (under the old regulations) and later equated under Ordinance № 5 of the second 
PQD. This situation is expected to change in the coming years to increase the share of pedagogical specialists with professional qualifications. Ordinance №15 on the status and professional development of teachers, principals and other pedagogical specialists allows teachers with 2 years of pedagogical experience to apply for a fifth PQD. It can also be assumed that the efforts of some teachers (5\%), who do not have a qualification degree, will be aimed at raising their qualification due to the fact that under the new rules they will not be able to continue their career development without qualification degrees. The awarded professional qualification degrees are concrete proof that the pedagogical specialists are involved in lifelong learning by increasing their knowledge, skills and competencies through various forms (training courses, self-study), which is validated through the PQD certificates issued from the departments for the qualification of the pedagogical specialists at the higher schools.

The distribution according to the pedagogical experience of the participants in the survey is related to the professional experience of the participants and it is established that the most numerous is the group of pedagogical specialists with over 25 years of pedagogical experience $-38 \%$, followed by those with 21 to 25 years of experience, (17\%), between 16-20 years $-13 \%$, and the least number of teachers with experience from 6 to 10 years $(8 \%)$. There is a tendency of an increase in the number of teachers with pedagogical experience of up to 5 years. However, it cannot be said that this $13 \%$ includes only young teachers up to the age of 35 , as there are also newly appointed teachers who have returned to the profession.

The pedagogical specialists from the regional and large cities (including the capital) are almost evenly represented in relation to the small towns and villages. The results show that some of the respondents live and work in regional cities, the situation is similar for those living in the big city and the small town. Although only by $8 \%$, there is a difference in the place of residence and place of work of the pedagogical specialists living in the capital, who have to travel and work in the smaller settlements around it. The data show that the largest difference between the place of work and residence is observed among those who live in rural areas but work in a city (larger or smaller), which is explained by the tendency to optimize the network and structure of educational institutions influenced by demographic processes.

In the second block of questions related to the portfolio, as an appropriate tool for student assessment, a large part of the respondents (75\%) believe that students show initiative and activity in its preparation and it gives a clear picture of their formative assessment. Other (25\%) teachers state that it does not give a complete picture of their achievements, or have a neutral position. (Figure 1)

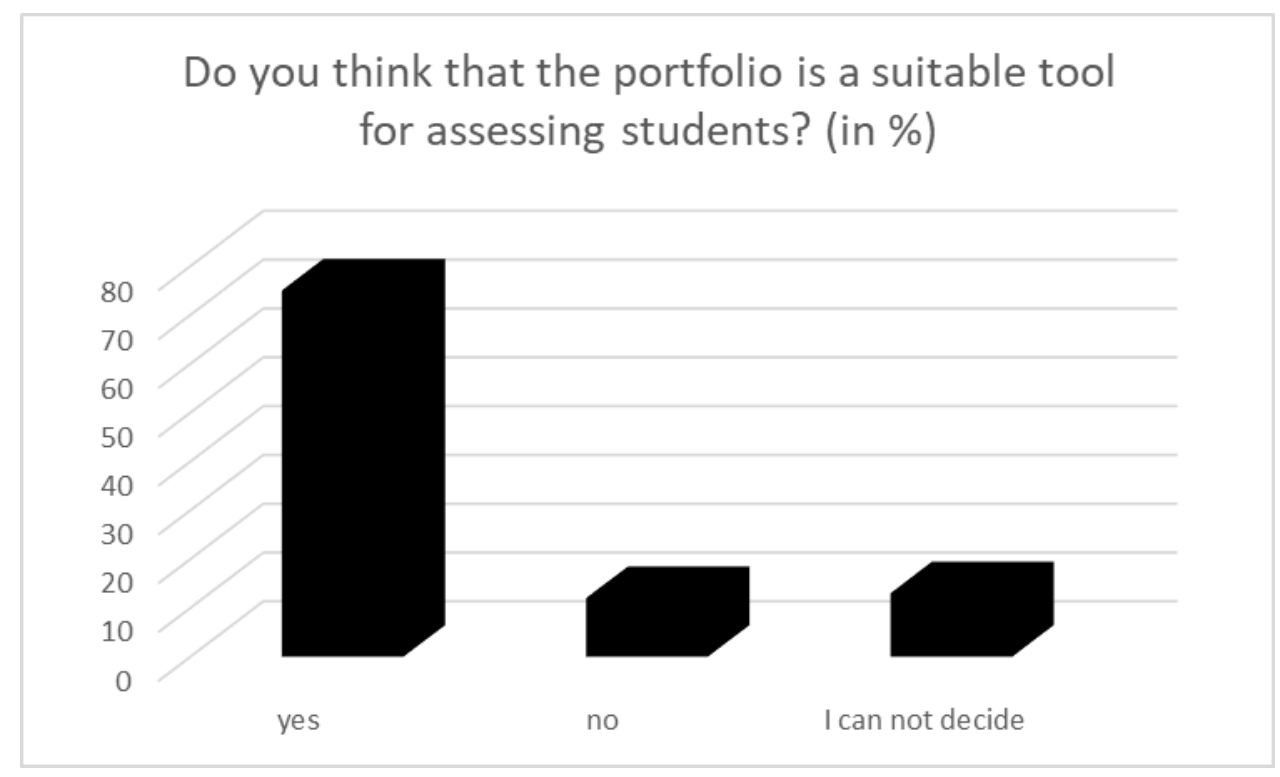

Figure 1. The portfolio as means for assessment 
Almost all respondents (78\%) define the formative assessment of students as an important condition for positive changes in Bulgarian education. The pedagogical specialists see the effect of the initiative and creativity shown by the students in the preparation and presentation of their portfolio. (Figure 2)

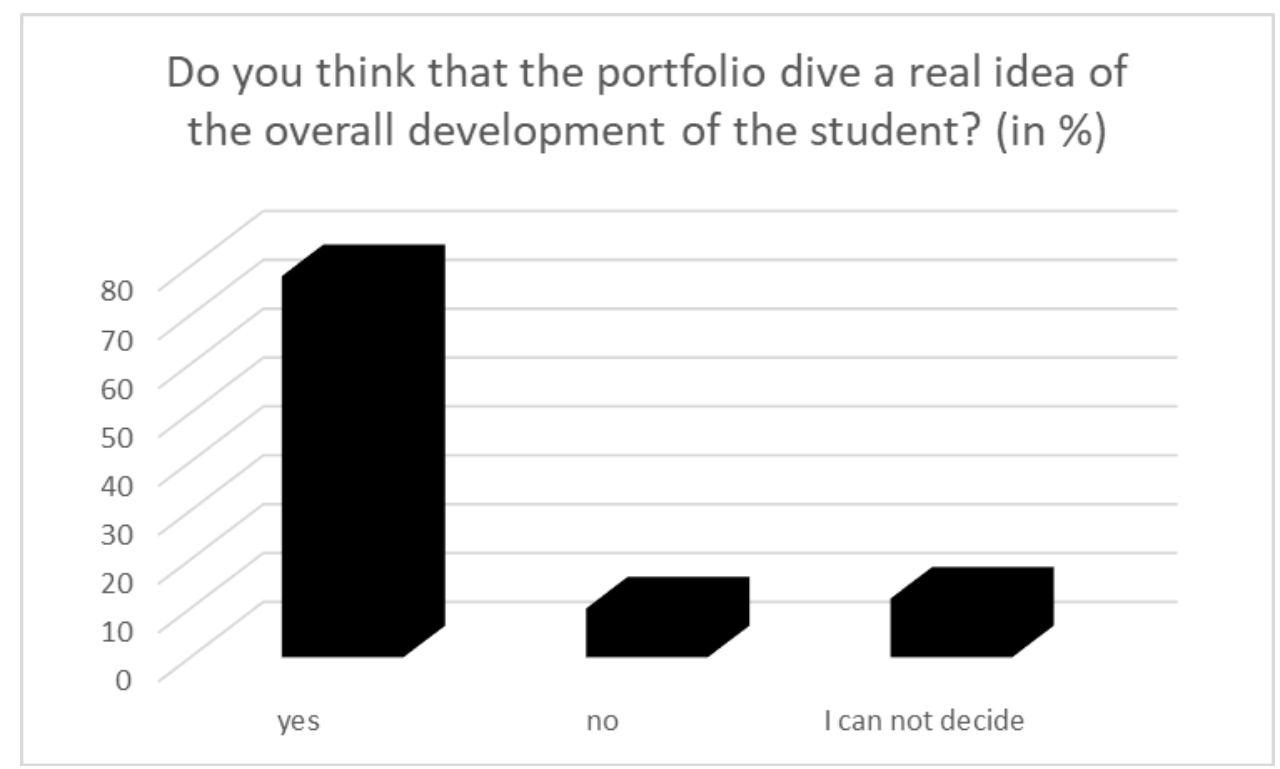

Figure 2. The portfolio as means for development of students

To the question "How do you feel about the opportunity for students participating in the assessment to have the right for a free choice for self-assessment?" - 54\% of the teachers say that students cope, $24 \%$ partially agree and $22 \%$ do not approve of students' free choice.

(Figure 3)

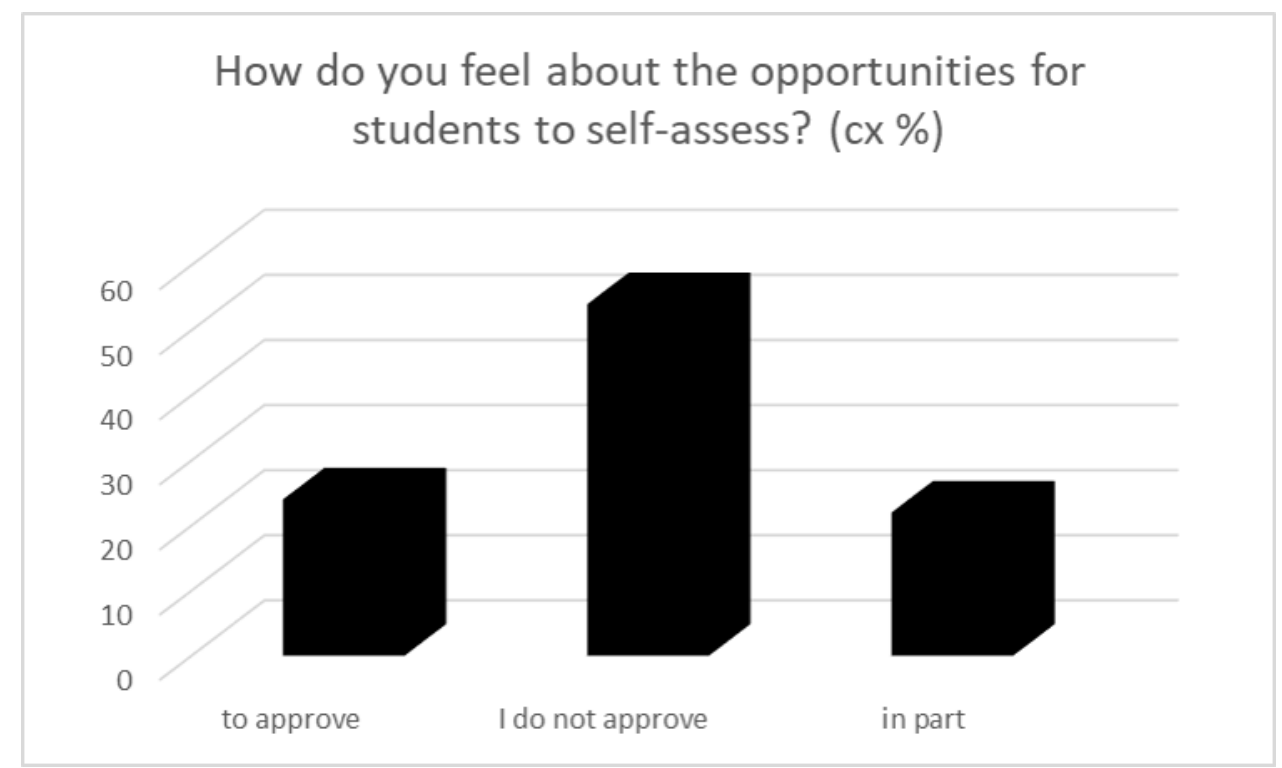

Figure 3. The portfolio as means for self-assessment of students

To the question - How do you feel about the possibility for students participating in the assessment, to have personal freedom in decision-making, if they are not satisfied with the work done? - 58\% of the educators are positive about free decision-making, 24\% still have doubts about students' ability to argue and $28 \%$ are sceptical.
To the question - Do you think that the student portfolio gives a real idea of the overall development of the student? - 78\% of the pedagogues give a positive answer, pointing to the free answer questions with the high performance of this type of assessment, $12 \%$ are of the opinion that only half of the students 
are successful and only $10 \%$ do not achieve results through the portfolio method.

\section{CONCLUSIONS}

In conclusion, it can be summarized that, in general, teachers evaluate positively the use of the portfolio to achieve the goals of the formative assessment of students. According to the respondents, the inclusion of activities for the preparation of a folder with evidence of development and progress activates students and creatively inspires them.

In the opinion of most of the teachers, it is necessary not only to change the state of educational standards for assessment, but also to conduct more mass training courses to improve the work in this field.

Teachers face difficulties in their work regarding the assessment of students. Impressive are the answers of many of them that they are not familiar with the formative assessment and the portfolio as a tool for diagnosing student achievement.

It can be said that innovative assessment methods have a stimulating effect on purposeful work to achieve the goals of the educational process.

The creation and maintenance of the student portfolio is an appropriate tool for a fair formative assessment of the work done. It fulfils the set purposes for which it was created.
MIRCHEVA V., et al.

The effectiveness of the use of the portfolio corresponds to the idea of humanizing the school environment by improving the results of the development and learning of students in school. Once introduced as a technique and practice for assessing and certifying academic achievement, it can also serve the purposes of formative assessment and for measuring the quality of the educational process. The student portfolio contributes to a change in personal terms, as well as in intellectual and cultural development. Its role is to bring the student to a higher level of self-esteem, to develop his creativity and positivity in the work at school. The introduction and use of this widely used European practice through the portfolio can limit the subjectivity of evaluation.

\section{ACKNOWLEDGMENTS}

The article was developed as a result of work on a project: №80-10-90/15.04.2020 from 2020. on NIS - Sofia University "St. Kliment Ohridski" - on the topic: Research of the possibilities of the portfolio as a tool for formative assessment in the educational process.

\section{REFERENCES}

1. Velchev, I. Evaluation as improving the quality of education. K., el.mag. LiterNet, 2004.

2. Andreev, M. Assessment in school. S., Univ. ed. "St. Kliment Ohridski", 1995.

3. Cerbin,W. The course portfolio.www.psychologience.org/observer/0401/tip s.html 